MATEC Web of Conferences 44, 02003 (2016)

DOI: $10.1051 /$ matecconf/20164402003

(C) Owned by the authors, published by EDP Sciences, 2016

\title{
The Analysis of The Fault of Electrical Power Steering
}

\author{
Li Wen Zhang, Rong Du and Yan Cheng ${ }^{1}$ \\ ${ }^{1}$ Hebei Jiaotong Vocational \& Technical College
}

\begin{abstract}
This paper analysis the common fault types of primary Electrical Power Steering system, meanwhile classify every fault. It provides the basis for further troubleshooting and maintenance. At the same time this paper propose a practical working principle of fault-tolerant, in order to make the EPS system more security and durability.
\end{abstract}

\section{Introduction}

Electrical Power Steering system (EPS) System compareing to traditional mechanical hydraulic steering system has good steering agility, steering stability, lowtemperature resistance and low power consumption. Moreover it has the advantages of easy integration of secondary development. Thus it shows strong vitality in the power steering systems of automobile, and will gradually replace the conventional steering system. EPS had entered the stage of mass production in some other countries, and had become the vehicle parts of high-tech products.

As a new technology, EPS is not as mature as traditional technology. However, the output of traditional steering is not independent of the input, and EPS can do this depending on the motors. Comparing to the hydraulic power steering, EPS may has different failure modes, it is very necessary to identify and research the potential failure modes.

This paper analyzes the most common fault conditions such as fault in torque sensor the vehicle speed sensor, and proposes fault tolerant method combined with the corresponding technical, and make the adaptability of troubleshooting. Structure and

\section{The structure and working principle of ESP}

The structure and working principle of ESP is shown in Figure 1.

ESP system consists of speed sensors, steering wheel torque sensors, speed sensors, controllers, power driver circuit, flash memory, clutch and DC motor and other components. The controller determines the rotational direction and best assist torque of the motor according to the output signal of each sensor, and send control signals to the motor and clutch, and control the rotation of the DC motor by the power driving circuit.
The output of motor drive gear and rack mechanism to produce steering power after the effect of decelerating the rotation speed to multiply the torque by the reduction mechanism.

By precise control algorithm, the motor torque can be discretionarily changed, so that the transmission mechanism can get any required value.

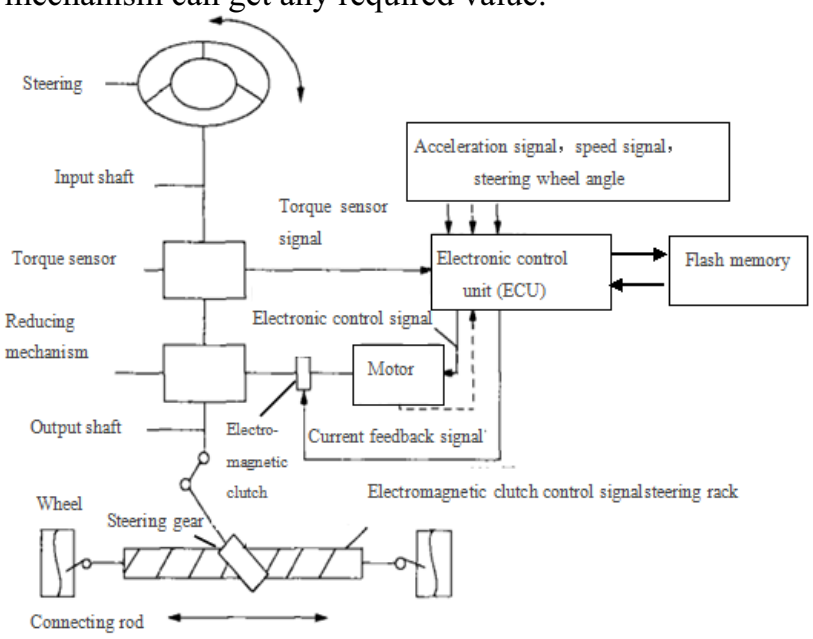

Figure 1. The structure and working principle of ESP

\section{The principle and common failure modes of sensor}

\subsection{Torque sensor}

Torque sensor measures the torque between the steering wheel and steering output shaft, and converts its value to a voltage signal to the ECU, which is an important determinant.to control the value of the power steering. Therefore, the validity of the output signal directly affects the manipulation safety of vehicles, especially high-speed of moving vehicles. Currently used torque sensors can be divided into contact sensor and non-contact sensor. The contact sensor is always swing-arm-type. The non- 
contact sensor is always inductance-type. This paper mainly analyses the failure modes of these two kinds of mainstream torque sensors

Figure 2 is typical structure of contact torque sensor. There is a torsion bar on the steering shaft. This device which using a potentiometer to output two independent primary signal and secondary signal by the deformation of the torsion bar, get torque and direction signal. Relatively speaking, contact structure is complex, because of that the wear of mechanical components it is easy to cause the sensor errors. For those sensors which use potentiometer to measure displacement, the wearing out of the potentiometer element also may cause the sensor errors. This kind of sensor always uses $5 \mathrm{~V}$ power supply. Its output signal has 5 ways. P1, P2, P3 are used to provide information of angle, while $\mathrm{T} 1, \mathrm{~T} 2$ are used to provide information of torque. Actually The signal P1 and P3 can provide sufficient information for calculate angle and the signal P2 was not necessary for the calculation of angle, it is a redundant communication channel. The signal $\mathrm{T} 1$ and $\mathrm{T} 2$ both have sufficient information for calculate torque, so they are redundant communication channels for each other. This design is facilitate not only for fault detection, but also for playing a backup role after a signal failure, in order to do fault tolerance and troubleshooting.

Figure 3 is typical structure of non-contact torque sensor. Leakage magnetic ring is riveted on the input shaft rotating with the input shaft. There is rack on the input shaft. Leakage magnetic ring has two rows of windows, respectively corresponding to sensor coil L1 and L2. The two coils are assembled in shell of the sensor, as shown in Figure 3. The working principle is based on the electromagnetic induction, and realize measurement by the change of coil inductance or mutual inductance.

After several experimental research and data analysis, and combining with relevant literature, we come to the conclusion of their failure modes, which is shown as table 1 .

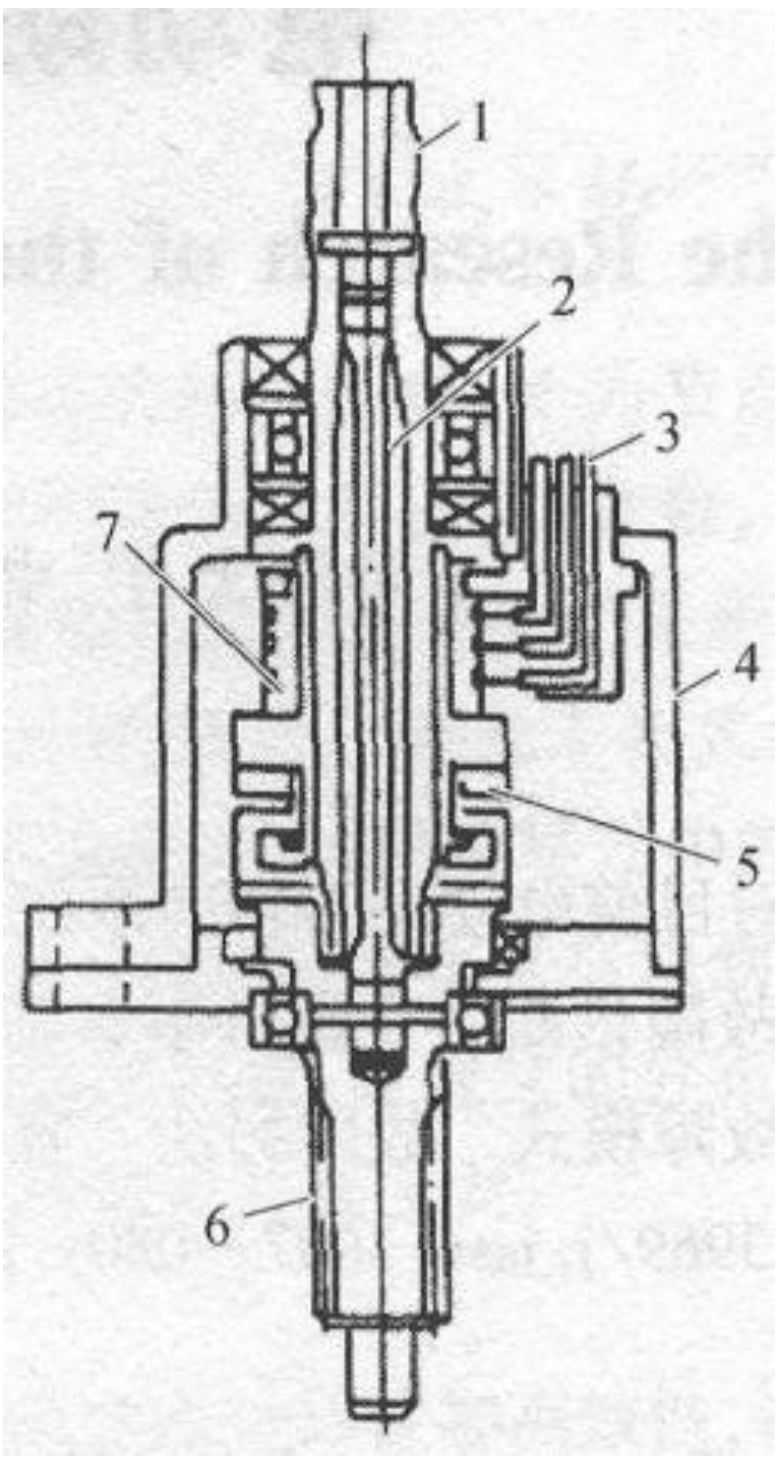

Figure 2. Contact torque sensor

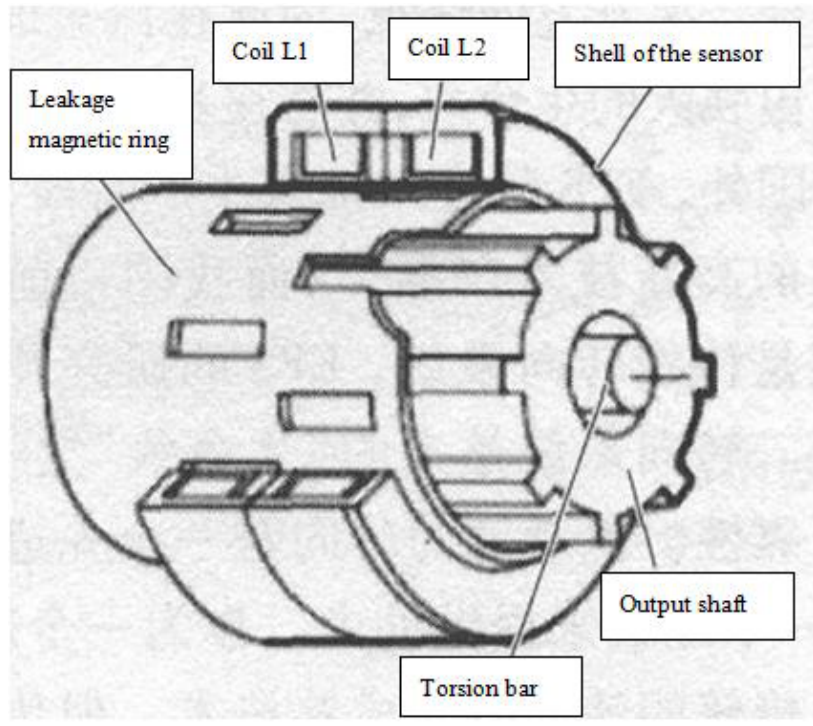

Figure 3. Non-contact torque sensor 
Table 1. Failure modes of torque sensors.

\begin{tabular}{|c|c|c|}
\hline Sensor type & Failure event & Failure reason \\
\hline \multirow{5}{*}{ Contact torque sensor. } & $\begin{array}{l}\text { Primary signal and } \\
\text { secondary signal } \\
\text { inconsistencies. }\end{array}$ & $\begin{array}{l}\text { Mechanical structural } \\
\text { failure or wear. }\end{array}$ \\
\hline & $\begin{array}{c}\text { Power supply voltage is } \\
\text { too high or too low. }\end{array}$ & Battery power is low. \\
\hline & $\begin{array}{l}\text { Auxiliary line open } \\
\text { circuit }\end{array}$ & $\begin{array}{c}\text { Corrosion or Foreign } \\
\text { body }\end{array}$ \\
\hline & Mechanical failure & $\begin{array}{c}\text { Crashing, Design } \\
\text { defects }\end{array}$ \\
\hline & Signal mixing & $\begin{array}{c}\text { Noise circumstances, } \\
\text { poor road condition }\end{array}$ \\
\hline \multirow{4}{*}{ Non-contact torque sensor. } & Short circuit & $\begin{array}{l}\text { pencil of lines short } \\
\text { circuit }\end{array}$ \\
\hline & Open circuit & $\begin{array}{c}\text { Lead-out wire is fault } \\
\text { soldered joint }\end{array}$ \\
\hline & $\begin{array}{l}\text { The voltage difference } \\
\text { between coil L1 and L2 } \\
\text { is higher than } 30 \mathrm{mV}\end{array}$ & $\begin{array}{c}\text { Bad contact of coil L1 } \\
\text { or L2 }\end{array}$ \\
\hline & $\begin{array}{l}\text { String makes noise, } \\
\text { stagnates or jitters. }\end{array}$ & $\begin{array}{c}\text { Motor connector parts } \\
\text { contact are loose, and } \\
\text { bad contact. }\end{array}$ \\
\hline
\end{tabular}

\subsection{Speed sensor}

Speed sensor of ESP system is used for detecting the rotating speed of tire, and generate the proportional signal base on the rotating speed. Figure 4 is typical structure of speed sensor.

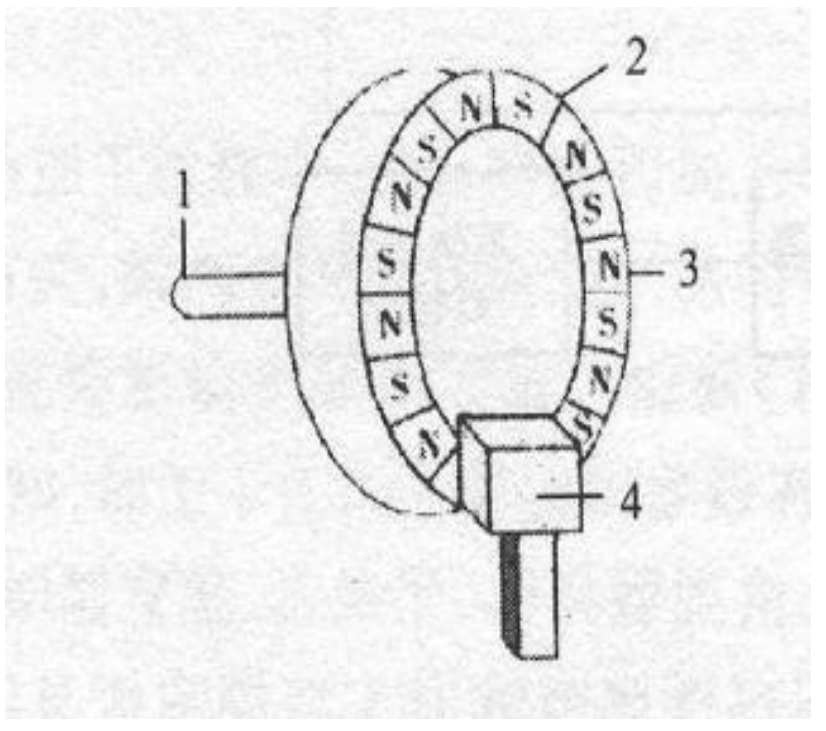

Figure 4. Typical structure of speed sensor

The working principle of speed sensor is that when the input shaft is rotating, the Hall switch integrated sensor fixed near magnetic turntable can produce a corresponding pulse in each place passed by small magnets. By detecting the number of pulses generated per unit time, we can measure the rotating speed of the input shaft. It can generate a sine pulse which has a frequency that proportional to the speed. This sine pulse change to a square wave signal by the circuit of the odometer. This square wave signal is used by odometer, and at the same time it is transmitted to ESP controller by wire for providing speed signal. Base on the speed signal, ESP provide corresponding auxiliary force. Commonly it provide a larger force at low speed so as to make steering lightly while it provide a smaller force at high speed so as to increase road feeling and operational stability. Likewise, we come to the conclusion of it failure modes, which is shown as table 2 .

\section{EPS working principle of fault-tolerant}

Base on the above research and analysis of failure modes of sensors, we have found a new design for troubleshooting. To improve the reliability and safety of the vehicle, we add a flash memory in the ESP system and control by database. When the sensor malfunctions, the system may get the correct sensor data signal combination directly from the database in the flash memory. ECU use this dependable data signal to control the motor to provide correct auxiliary force sequentially, in order to make the ESP system subject to the minimum extent affect and work unceasingly and steadily.

Figure 5 is the logic work flow fault-tolerant principle. The primary work flow of the system is that firstly system analyses the data signal from every sensor, if the signal is regular, corresponding memory space stores this regular signal, and if the signal show that the sensor malfunctions, the system will do some appropriate treatment by fault-tolerant principle, the system will work unceasingly and steadily as well as the fault indicator lights in order to remind the driver that the sensor malfunctions and need to be repaired or be changed. When the torque sensor and speed sensor malfunction at the same time. ECU will disconnect the clutch and make the ESP system stop doing the wrong operation and switch to mechanical steering system. 
Table 2. Failure modes of speed sensors.

\begin{tabular}{|c|c|c|}
\hline Sensor type & Failure event & Failure reason \\
\hline Open circuit. & Mildew or corrosion. \\
\cline { 2 - 3 } & Can`t connect to ECU. & Splice damage. \\
\cline { 2 - 3 } & Short circuit & $\begin{array}{c}\text { Pencil of lines short } \\
\text { circuit. }\end{array}$ \\
\cline { 2 - 3 } & Internal fault. & $\begin{array}{c}\text { From a high speed } \\
\text { drop into a low speed. }\end{array}$ \\
\cline { 2 - 3 } & Bad contact. & Splice falls off. \\
\hline
\end{tabular}

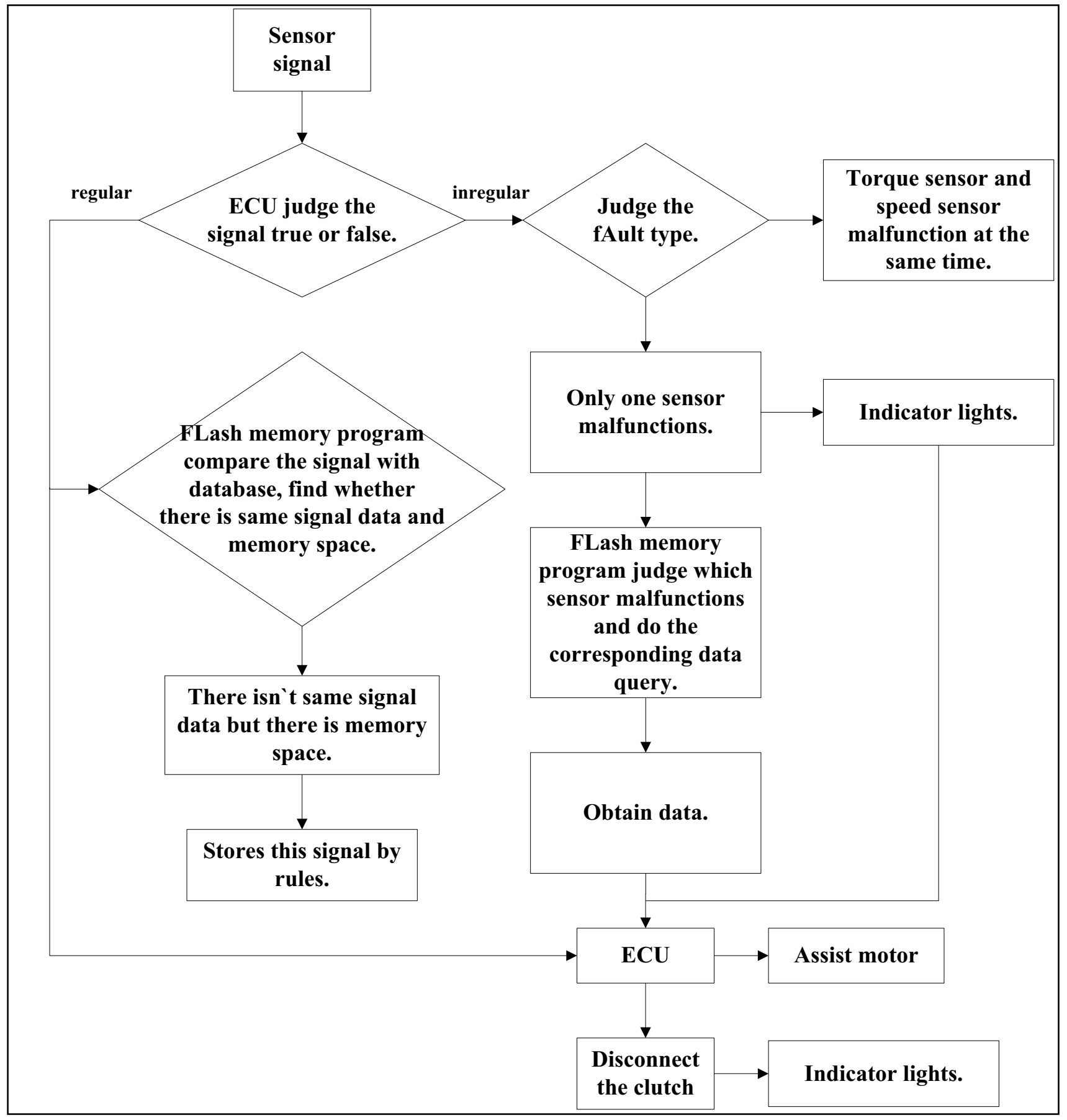

Figure 5. Logic work flow fault-tolerant principle 


\section{Conclusion}

(1) Whether the ESP system reliable or not, that is rely on the sensor signal, so that the analysis of the common faults of the sensor is very important. This article analysis the common fault types and provides the basis for further troubleshooting and maintenance.

(2) This article use the fault-tolerant principle found a new design for ESP system. When the sensor malfunctions, the fault indicator lights, the program judges the signal and do the corresponding data query, so as to obtain the correct data and sent it to ECU. This design make the ESP system can work unceasingly and steadily during a period of time and can keep the assistant performance when the sensor malfunctions.

\section{References}

1. Osuka A, Mastuoka Y, Tsustui T, et al. Development of Pinion-Assisted Type Electric power Steering.KOYO Engineering Journal English Ediiton No.161E (2002)

2. Aly Badawy, Dieter Fehlings. Development of a New Concept of Electrically Powered Hydraulic Steering $[\mathrm{J}]$. SAE transactions, 2004, 113( 6) : $1074-1081$

3. Wolfgang KemmetmüllerModeling and Nonlinear Control of an Electro-hydraulic Closed center Power-steering System [C]//Proceeding of the 44th IEEE Conference on Decision and Control. [S. 1. ] : [s. n. ] , 2005: 50775082

4. Guo Xiaolin, Ji Xuewu, Liu Yahui, et al. Study on Dynamic $\mathrm{R}$ esponses of the vehicle Handing Models with a Speed-sensitive Hydraulic Power Steering System [J] Training, 2013: 10-11. 